\title{
Prepubertal unilateral gynecomastia in the absence of endocrine abnormalities
}

\author{
Min Kang, MD', \\ Chan Jae Lee, MD', \\ II Tae Hwang, MD, PhD², \\ Kwanseop Lee, MD, $\mathrm{PhD}^{3}$, \\ Min Jae Kang, $M D^{1}$
}

'Department of Pediatrics, Hallym University Sacred Heart Hospital, Hallym University College of Medicine, Anyang, ${ }^{2}$ Department of Pediatrics, Hallym University Kangdong Sacred Heart Hospital, Hallym University College of Medicine, Seoul, ${ }^{3}$ Department Diagnostic Radiology, Hallym University Sacred Heart Hospital, Hallym University College of Medicine, Anyang, Korea

Received: 30 July, 2014

Revised: 20 August, 2014

Accepted: 28 August, 2014

Address for correspondence:

Min Jae Kang, MD

Department of Pediatrics, Hallym University Sacred Heart Hospital, 22 Gwanpyeong-ro 170beon-gil, Dongan-gu, Anyang 431-796, Korea

Tel: +82-31-380-3730

Fax: +82-31-380-1900

E-mail:mjkang@hallym.or.kr
Gynecomastia is defined as the excessive development of breast tissue in males, which can occur as unilateral or bilateral. Although the overall prevalence of gynecomastia is $40 \%-65 \%$, the prepubertal unilateral gynecomastia in the absence of endocrine abnormalities is unusual, with only a few case reports in literature. Idiopathic gynecomastia in prepuberty is benign but a diagnosis of exclusion. We here report two cases of healthy prepubertal boys aged 8.8 and 9.6 years old, respectively, presented with painful palpable mass in their unilateral breast. Breast tissue with glandular proliferation was confirmed on ultrasonography. Serum levels of estradiol, testosterone, and other laboratory findings were within normal range. They seem to have the prepubertal idiopathic gynecomastia but further follow-up to see their progression is needed.

Keywords: Gynecomastia, Child, Prepuberty

\section{Introduction}

Gynecomastia is the benign glandular proliferation of male breast tissue which accounts for $60 \%$ of all disorders of male breast ${ }^{1)}$. It can be unilateral or bilateral, symmetrical or asymmetrical, and painless or tender mass from the acute nonspecific stretching of tissues ${ }^{1,2)}$. Physiologic gynecomastia can appear bilaterally or unilaterally ${ }^{3}$ and age specific incidence rates are high in the neonatal period, early to midpuberty, and old age. An estimated 60\%$90 \%$ of neonates have transient gynecomastia, which can occur due to placental transfer of estrogens from mother to child $\mathrm{d}^{4}$. It is known to disappear spontaneously within 4 weeks of age. Pubertal gynecomastia results from the imbalance between estrogens and androgens within the breast tissue and occurs in as many as $70 \%$ of adolescent boys. Seventy-five percent of pubertal gynecomastia resolves within 1-3 years of onset without treatment ${ }^{1)}$. Among 50 - to 80 -year-old men, decreased production of testosterone and increased peripheral conversion of androgens to estrogen especially in adipose tissue results in gynecomastia which increases with aging ${ }^{5}$.

Prepubertal gynecomastia is characterized by the presence of palpable unilateral or bilateral breast tissue in boys without other signs of sexual maturation ${ }^{6}$. The prepubertal gynecomastia is not well known and there are only a few case reports in the literature. Because it is generally thought to be pathological, idiopathic prepubertal gynecomastia is a diagnosis of exclusion and a careful history, meticulous physical examination, and pertinent laboratory studies should be performed to exclude the possible pathologic causes ${ }^{7}$. We here report the two cases of unilateral gynecomastia in prepubertal boys without other specific symptoms or signs. 


\section{Case reports}

\section{Case 1}

A 9.6-year-old boy visited outpatient clinic with right nipple tenderness for 2 months. Drugs or dermal applications containing herb materials or estrogens were not used for at least 3 months before visit except for the 5 days of antihistamine drug for allergic rhinitis. There was no acceleration of growth velocity recently and he had no symptoms of galactorrhea. Developmental milestone and school achievement was normal. Family history of breast malignancies or gynecomastia was denied. Generally he was not so ill-looking and his height, weight, and the body mass index (BMI) were $135.6 \mathrm{~cm}$ (50th75th percentile), $37.5 \mathrm{~kg}$ (75th-90th percentile), and $20.4 \mathrm{~kg} /$ $\mathrm{m}^{2}$ (75th-85th percentile), respectively. Tanner stage 2 of right breast sized $1.5 \mathrm{~cm} \times 1.5 \mathrm{~cm}$ was palpable with tenderness. There was no redness or local heatness on the right breast and the color change or pigmentation of the right nipple was not found. The left breast showed normal, Tanner stage 1, on inspection and palpation. Testis was palpable symmetrically and their

\section{Table 1. Laboratory results of cases}

\begin{tabular}{lccc}
\hline Variable & Case 1 & Case 2 & Normal range \\
\hline TSH (ulU/mL) & 2.94 & 3.43 & $0.7-6.4$ \\
Free T4 $(\mathrm{ng} / \mathrm{dL})$ & 1.31 & 1.12 & $0.8-2.2$ \\
$\mathrm{LH}(\mathrm{mlU} / \mathrm{mL})$ & $<0.10$ & 0.43 & $0.02-0.3$ \\
FSH $(\mathrm{mlU} / \mathrm{mL})$ & 1.28 & 1.91 & $0.26-3.0$ \\
Estradiol $(\mathrm{ng} / \mathrm{dL})$ & $<0.5$ & $<0.5$ & $<1.5$ \\
Testosterone $(\mathrm{ng} / \mathrm{dL})$ & $<0.025$ & $<0.025$ & $<3-10$ \\
IGF-1 $(\mathrm{ng} / \mathrm{mL})$ & 203 & 112 & $136-385$ \\
IGFBP-3 $(\mu \mathrm{g} / \mathrm{mL})$ & 4.2 & 3.4 & $2.1-4.2$ \\
AST $(I U / L)$ & 33 & 29 & $8-38$ \\
ALT $(I U / L)$ & 18 & 10 & $5-43$ \\
\hline TSH & & 10 &
\end{tabular}

TSH, thyroid-stimulating hormone; LH, luteinizing hormone; FSH, follicle-stimulating hormone; IGF-1, insulin like growth factor-1; IGFBP-3, insulin like growth factor binding protein-3; AST, aspartate aminotransferase; ALT, alanine aminotransferase. volume was $2 \mathrm{~mL}$ for each. Phallus and pubic hair were Tanner stage 1 and genital ambiguity was not found. His thyroid and liver function was normal and serum levels of gonadotropin and sex steroids were within normal range. The serum levels of insulin like growth factor-1 (IGF-1) was $203 \mathrm{ng} / \mathrm{mL}$ (25th-50th percentile) and insulin like growth factor binding protein-3 (IGFBP-3) was $4.16 \mathrm{ng} / \mathrm{mL}$ (90th-97th percentile) (Table 1). Bone age revealed as 11 years. Ultrasound image of breast showed prominent breast tissue in the right without cysts or signs of malignancy and normal in the left (Fig. 1). Ultrasound images of testis and adrenal glands showed normal.

After 3 months of visit, the right breast regressed with only tiny palpable mass left without tenderness. And he was still in prepuberty.

\section{Case 2}

A 8.8-year-old boy visited outpatient clinic with left breast enlargement for several weeks. He complained of pain and tenderness of his left breast at the start, but symptoms improved after few days. Antipyretics were used about a week ago for 3 days because of upper respiratory infection and no other drugs or dermal applications containing estrogenic materials for at least 3 months before visit were used. There was no acceleration of growth velocity recently and he had no symptoms of galactorrhea. Developmental milestone and school achievement was normal. There was no family history of breast malignancies or gynecomastia. Generally he was not so ill-looking and his height, weight, and the BMI were $129 \mathrm{~cm}$ (25th-50th percentile), $22.5 \mathrm{~kg}$ (5th percentile), and $13.5 \mathrm{~kg} / \mathrm{m}^{2}(<3 \mathrm{rd}$ percentile), respectively. There was a noticeable asymmetry of breasts with Tanner stage 2 of the left, sized $2.0 \mathrm{~cm} \times 1.5 \mathrm{~cm}$ with mild tenderness on palpation. There was no redness or local heatness on the left breast and the color change or pigmentation of the left nipple was not found. The right breast showed normal, Tanner stage 1 on inspection and palpation. Testis was palpable symmetrically and their volume was $2 \mathrm{~mL}$ for each. Phallus and pubic hair were Tanner stage 1 and genital ambiguity was not
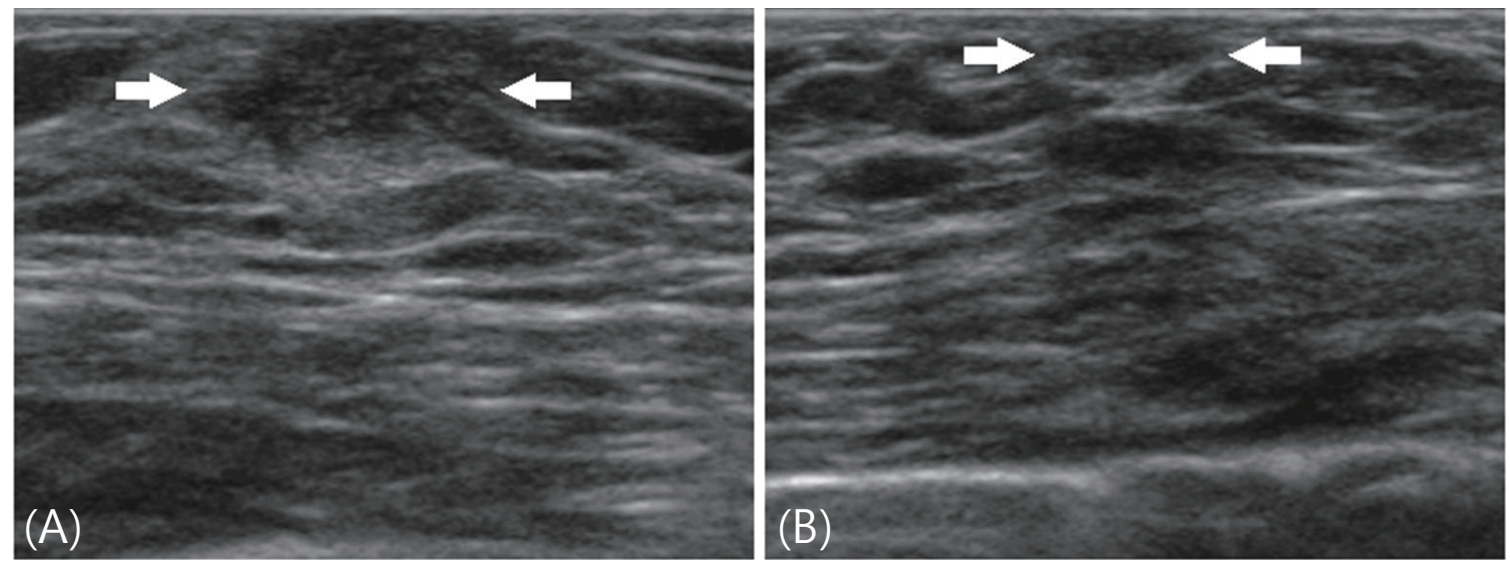

Fig. 1. The ultrasound images of case 1 showed a hypoechoic and solid lesion (arrows) without signs of malignancy in the retroareolar area of the right breast (A) and normal in the left breast (B). 
found. His thyroid and liver function was normal and serum levels of gonadotropin and sex steroids were within normal range. The serum levels of IGF- 1 was $112 \mathrm{ng} / \mathrm{mL}$ (3rd-10th percentile) and IGFBP-3 was $3.40 \mathrm{ng} / \mathrm{mL}$ (90th-97th percentile) (Table 1). Bone age revealed as 7 years. Ultrasound image of breast showed normal in the right and prominent breast tissue in the left (Fig. 2). Ultrasound images of testis and adrenal glands showed normal.

After 3 months of visit, the size of palpable mass on the left breast showed no interval change. However, pain and tenderness was completely disappeared. And he was still in prepuberty.

\section{Discussion}

According to a study of Israel, prepubertal gynecomastia was diagnosed in 29 out of 581 boys (5\%) with gynecomastia). Their mean age at diagnosis was $8.9 \pm 2.2$ years which was consistent with our cases. In a report of 20 Korean boys with gynecomastia, younger than 15 years of age, only 2 boys were prepubertal $^{8)}$. Although it is a rare condition, a finding of breast enlargement in a prepubertal boy requires an extensive medical evaluation and clinical follow-up of the pubertal development in order to rule out endocrinopathies, such as hyperaromatase syndrome, and neoplasms that produce estrogen or human chorionic gonadotropin ${ }^{9)}$. Hormonal aberrations that cause pathological gynecomastia include absolute or relative estrogen excess resulting from exogenous administration, endogenous overproduction, increased peripheral conversion of androgens to estrogens, androgen deficiency, or androgen insensitivity ${ }^{10)}$.

The absolute or relative androgen deficiency related pathologic gynecomastia can be seen with any form of inherited or acquired hypogonadism ${ }^{2)}$. The most common chromosomal disorder associated with hypergonadotropic hypogonadism is Klinefelter syndrome ${ }^{2)}$. The reported prevalence of gynecomastia in Klinefelter syndrome is said around $40 \%{ }^{11)}$. Aromatase excess syndrome (AES) is associated with increased peripheral aromatization of androgens to estrogens and shows similar manifestations to those of Sertoli cell or feminizing adrenocortical tumors ${ }^{12)}$. AES is a rare entity characterized by accelerated early linear growth, prepubertal gynecomastia, and testicular failure in men ${ }^{13)}$. Stratakis et al. ${ }^{13)}$ described AES as a cause of the unusual entity of familial gynecomastia. Increased estrogen production and aromatase expression in Sertoli cell tumors associated with Peutz-Jeghers syndrome also can cause prepubertal gynecomastia ${ }^{14)}$. Gynecomastia is reported as the rare presenting symptom in patients with nonclassic type of
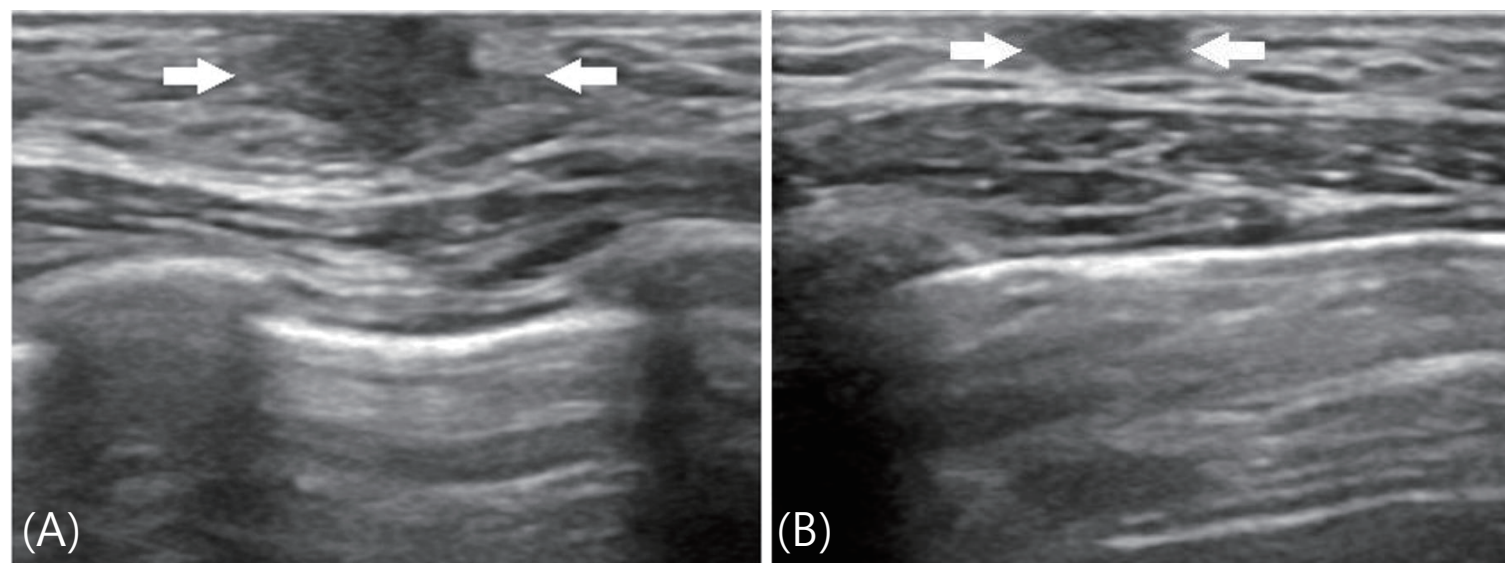

Fig. 2. The ultrasound images of case 2 showed a hypoechoic and solid lesion (arrows) with irregular margins in the retroareolar area of the left breast (A) and normal in the right breast (B).

Table 2. Drugs associated with gynecomastia

\begin{tabular}{|c|c|}
\hline & Drug \\
\hline Hormones ${ }^{\text {a) }}$ & Androgens, anabolic steroids, estrogens, estrogen agonists, hCG \\
\hline Antiandrogens or Inhibitors of androgen synthesis & Bicalutamide, flutamide, nilutamide, cyproterone, GRH agonists (leuprolide and goserelin) \\
\hline Antibiotics & Metronidazole, ketoconazole ${ }^{a}$, minocycline, isoniazid \\
\hline Antiulcer medications & Cimetidine $^{a}$, ranitidine, omeprazole \\
\hline Chemotherapeutic agents & Methotrexate, alkylating agents, vinca alkaloids \\
\hline Cardiovascular drugs & $\begin{array}{l}\text { Digoxin }{ }^{\text {a) }} \text {, ACEls (captopril, enalapril), CCBs (diltiazem, nifedipine, verapamil), amiodarone, } \\
\text { methyldopa, spironolactone, reserpine, minixidil }\end{array}$ \\
\hline Psychoactive agents & Anxiolytic agents (diazepam), TCA, phenothiazines, haloperidol, atypical antipsychotic agents \\
\hline Miscellaneous & Antiretroviral therapy for HIV, metoclopramide, penicillamine, phenytoin, sulindac, theophylline \\
\hline
\end{tabular}


21-hydroxylase deficiency which is thought to be the result of peripheral aromatization of accumulated androgens ${ }^{15}$. Hyperthyroidism increases aromatization of androgens to estrogens and decreases free testosterone levels by increasing circulating sex hormone binding globulin levels which results in gynecomastia $^{2}$.

There are some debates but generalized obesity seems to be associated with the gynecomastia through increased aromatase activity in adipose tissue ${ }^{16)}$. According to the report, 9 of 29 prepubertal gynecomastia boys $(31 \%)$ were obese $^{6}$. The use of alcohol and illicit drugs, such as marijuana, heroin, methadone, and amphetamines is considered as possible cause of gynecomastia. It is hard to testify but the exposure to environmental chemicals ${ }^{17)}$, which have estrogen like effects, might also be involved in the pathogenesis of gynecomastia. Several herbal supplements, particularly those containing phytoestrogen and estrogen containing hair cream cause prepubertal gynecomastia and other numerous medications ${ }^{18)}$ are summarized in Table 2.

Though there are many pathologic causes as described above, a specific cause is rarely identified and over $90 \%$ of patients with prepubertal gynecomastia are revealed as idiopathic. Idiopathic and pathologic gynecomastia cannot be distinguished by the initial breast manifestation. Both idiopathic and AES have no accompanied symptoms except for the breast enlargement. But hormonal profiles and bone age may help in the discrimination. Einav-Bachar et al. ${ }^{5)}$ reported the hormonal levels of patients with idiopathic prepubertal gynecomastia were normal and within the prepubertal range, while two patients with AES showed increased estradiol and estrone levels. And usually, both boys and girls with the AES have greatly advanced bone age ${ }^{13)}$.

We did not perform all laboratory tests to rule out various pathologic causes. But glandular proliferation of their breast did not seem to progress and hormonal abnormalities were not found. And other symptoms suggesting pathologic gynecomastia were not revealed. Because both were within normal weight, obesity related increased aromatase activity was excluded. Case 1 demonstrated accelerated bone age compared to his chronologic age. But when considering that the predicted adult height lied within the target range, bone age acceleration is not likely to be pathologic. Additionally none of our cases were exposed to any medications of exogenous agents associated with gynecomastia. All things taken together, therefore, our cases would be benign and idiopathic.

We report two rare cases of prepubertal unilateral gynecomastia, which seem to be idiopathic. They are expected to progress as a benign course but further follow-up to see their pubertal progression and to check other labs such as chromosome study if needed should be performed.

\section{Conflict of interest}

No potential conflict of interest relevant to this article was reported.

\section{References}

1. Braunstein GD. Gynecomastia. N Engl J Med 1993;328:4905.

2. Narula HS, Carlson HE. Gynecomastia. Endocrinol Metab Clin North Am 2007;36:497-519.

3. Niewoehner CB, Nuttal FQ. Gynecomastia in a hospitalized male population. Am J Med 1984;77:633-8.

4. McKiernan JF, Hull D. Breast development in the newborn. Arch Dis Child 1981;56:525-9.

5. Einav-Bachar R, Phillip M, Aurbach-Klipper Y, Lazar L. Prepubertal gynaecomastia: aetiology, course and outcome. Clin Endocrinol (Oxf) 2004;61:55-60.

6. Nuttall FQ. Gynecomastia as a physical finding in normal men. J Clin Endocrinol Metab 1979;48:338-40.

7. Pescovitz $\mathrm{OH}$, Walvoord EC. When puberty is precocious: scientific and clinical aspects. New Jersey: Human Press Inc., 2007:204-14.

8. Kim JK, Oh KK, Yoon CS, Park JH. Etiological analysis of gynecomastia in children. J Korean Pediatr Soc 1998:41:224-9.

9. Berkovitz GD, Guerami A, Brown TR, MacDonald PC, Migeon CJ. Familial gynecomastia with increased extraglandular aromatization of plasma carbon19-steroids. J Clin Invest 1985;75:1763-9.

10. Ma NS, Geffner ME. Gynecomastia in prepubertal and pubertal men. Curr Opin Pediatr 2008;20:465-70.

11. Pacenza N, Pasqualini T, Gottlieb S, Knoblovits P, Costanzo PR, Stewart Usher J, et al. Clinical presentation of Klinefelter's syndrome: differences according to age. Int J Endocrinol 2012;2012:324835.

12. Shozu M, Sebastian S, Takayama K, Hsu WT, Schultz RA, Neely K, et al. Estrogen excess associated with novel gainof-function mutations affecting the aromatase gene. $\mathrm{N}$ Engl J Med 2003;348:1855-65.

13. Stratakis CA, Vottero A, Brodie A, Kirschner LS, DeAtkine $\mathrm{D}, \mathrm{Lu} \mathrm{Q}$, et al. The aromatase excess syndrome is associated with feminization of both sexes and autosomal dominant transmission of aberrant P450 aromatase gene transcription. J Clin Endocrinol Metab 1998;83:1348-57.

14. Kara C, Kutlu AO, Tosun MS, Apaydin S, Senel F. Sertoli cell tumor causing prepubertal gynecomastia in a boy with Peutz-Jeghers syndrome: the outcome of 1-year treatment with the aromatase inhibitor testolactone. Horm Res 2005;63:252-6.

15. Wasniewska M, Raiola G, Galati MC, Salzano G, Rulli I, Zirilli G, et al. Non-classical 21-hydroxylase deficiency in boys with prepubertal or pubertal gynecomastia. Eur J Pediatr 2008;167:1083-4.

16. Ersoz Ho, Onde ME, Terekeci H, Kurtoglu S, Tor H. Causes of gynaecomastia in young adult males and factors associated with idiopathic gynaecomastia. Int J Androl 2002;25:312-6.

17. Henley DV, Lipson N, Korach KS, Bloch CA. Prepubertal gynecomastia linked to lavender and tea tree oils. N Engl J 
Med 2007;356:479-85.

18. Johnson RE, Murad MH. Gynecomastia: pathophysiology, evaluation, and management. Mayo Clin Proc 2009;84: 1010-5. 